\title{
SOBRE O OBJETO DA FONOAUDIOLOGIA
}

\section{About the object of the Speech-Language Clinics}

\author{
Regina Maria Ayres de Camargo Freire ${ }^{(1)}$
}

\begin{abstract}
RESUMO
Este trabalho tematiza a questão do objeto em Fonoaudiologia, discute a pretensa unidade do campo e aponta a inexorabilidade de sua divisão para a concretização de seu estatuto científico. Para fazêlo assume a linguagem em seus processos patológicos sob a instância da clínica como seu objeto, mas indica a necessidade de se desnaturalizar a linguagem, redefinindo-a como instância simbólica de subjetivação. Isto a afasta definitivamente da Audiologia, aqui entendida como ramificação das ciências ditas biológicas, e do reducionismo a que tem sido submetida ao ser concebida apenas como prática. Por outro lado, instaura o fonoaudiólogo como clínico terapeuta, comprometido com a linguagem de seu paciente e sua cura. Reconhece, ainda, outra paternidade para a Fonoaudiologia, indicando a Lingüística e a Psicanálise - quando adotam as mesmas concepções de sujeito e de linguagem - como lugares de peculiar interesse na constituição do saber fonoaudiológico. Uma vez realocada a Fonoaudiologia terá, diante de sí, a tarefa de reconhecer a clínica como seu espaço privilegiado de problematização de questões, das quais a primeira será o enfrentamento da constituição de seu método clínico. Finalmente, alerta-se o fonoaudiólogo para a ameaça de nova dominação caso não se marque a distinção entre as formas de interpretação que identificam a clínica fonoaudiológica e a particularizam em relação à clínica psicanalítica.
\end{abstract}

DESCRITORES: Fonoaudiologia;Ciência ; Patologia de Fala e Linguagem; Linguagem

A questão do objeto ${ }^{1}$, quando se discute o estatuto de uma ciência em constituição, é prioritária. Penso ainda que as discussões desencadeadas a partir dos questionamentos que trago aqui, poderão ser extremamente frutíferas para a Fonoaudiologia enquanto ciência particular.

Confesso que, ao começar minhas reflexões sobre tema tão árido, assaltou-me uma dúvida paradoxal, desencadeada pela própria etimologia da palavra fonoaudiologia que, literalmente, significa o estudo (do som) da fala e da audição ou o discurso sobre (o som ) a fala e a audição. Pensei: seria possível que esta disciplina tivesse um duplo objeto? A tradicional divisão do campo profissional em audiologia e logopedia parecia confirmar a suspeita inicial. Fui então procurar na literatura

(1) Fonoaudióloga; Pós Dra. em Psicologia Educacional pela Universidade de São Paulo - USP; Dra. em Psicologia da Educação pela Pontifícia Universidade Católica de São Paulo - PUCSP; Profa. titular do Departamento de Clínica Fonoaudiológica da Pontifícia Universidade Católica de São Paulo.

Conflito de interesses: inexistente uma definição formal de Fonoaudiologia e penso que encontrei uma das primeiras, aquela assinada por Antonio Amorim², em 1972, que declara : "A Fonoaudiologia é o estudo integrado da linguagem humana e audição ..." . Deixando momentaneamente de lado a pertinência da definição, e tomando agora como ponto de partida as palavras do fonoaudiólogo, passei a questionar o que o autor estaria querendo dizer com essa afirmação. Avançando na leitura de suas considerações sobre a Fonoaudiologia e seu objeto, encontrei um outro momento em que o autor parece explicitar em que sentido está usando as palavras audição e linguagem. Diz ele: " A linguagem humana está relacionada com a audição. É através da audição que os homens identificam os sons, discriminam, memorizam e elaboram conceitos que são verbalmente transmitidos". Ora, fica aqui afastada a suposição de que a Fonoaudiologia teria dois objetos pois a afirmação de que o estudo da audição deva ocorrer integrado ao da linguagem indicia entre ambas uma relação (de causalidade? de implicação?), em que a primeira pode comprometer a integridade da segunda. Me explico melhor, a audição seria na 
verdade uma função biológica ou um conjunto de habilidades auditivas perceptuais tais como discriminação, atenção e memória que supostamente estariam na origem da então chamada recepção ou compreensão de linguagem. Portanto, em última instância, o objeto da Fonoaudiologia seria, ainda segundo a definição de Amorim, o estudo da linguagem, estando a audição no campo da complementaridade. Se de um lado isto afasta o fantasma do objeto duplo, por outro introduz uma certa concepção de linguagem cujo funcionamento estaria submetido ao da audição. Inicia-se aqui uma leitura equivocada que irá afastar a Fonoaudiologia da problematização e definição de seu objeto, retardando sua constituição possível e necessária enquanto campo particular de questões.

Quase dez anos mais tarde, há um retorno do que foi, provisoriamente, afastado do campo de reflexões desta disciplina em constituição. Este retorno irá re-instaurar a divisão, desta vez sob a letra da lei que, em 9 de dezembro de 1981, regulamenta a atividade profissional. Nela o fonoaudiólogo será definido como:" o profissional ..., que atua em pesquisa, prevenção, avaliação e terapia fonoaudiológicas na área da comunicação oral e escrita, voz e audição, bem como em aperfeiçoamento dos padrões da fala e da voz". E mais, é novamente o mesmo órgão público responsável pela redação da lei 6965 que, numa leitura apressada dessa definição, baixa uma resolução que ignora as questões que a própria Fonoaudiologia se coloca e esfacela seu objeto ao criar, precocemente, as chamadas especialidades profissionais em audição, voz, motricidade oral (fala?) e linguagem.

Isto traz, novamente, 'a cena, a questão do objeto em Fonoaudiologia que, num terceiro momento, o atual, irá deslocar o foco do "estudo da linguagem ou do discurso sobre a linguagem" para a "linguagem em sua instância patológica reafirmando a natureza essencialmente clínica da atividade fonoaudiológica"(parafraseando Ruth Palladino nas discussões sobre a reforma do curso de Fonoaudiologia).

Retomo a discussão anterior, desta vez deixando de lado a audição como suposto objeto da Fonoaudiologia, não só por já tê-la interpretado como complementar à linguagem mas também por supô-la objeto de outra ciência - a Audiologia. Prosseguiria interrogando o uso peculiar da forma distúrbios da comunicação, ora como paráfrase da palavra fonoaudiologia, ora como recobrimento dos termos: voz, fala e linguagem. Diria então que a natureza da pretensa separação entre esses elementos como objetos ou áreas particulares de conhecimento esteve desde sempre obscurecida. Parece-me ainda que, em muitas ocasiões, voz e fala são interpretados como elementos da linguagem, estabelecendo-se entre estes uma relação hierárquica de todo e partes. Voltando aos escritos de Amorim, pode-se observar, por exemplo, que 'voz' é definida como "um elemento da linguagem; é a produção que o ser humano faz, de sons, através das cordas vocais. É o elemento sonoro da comunicação". E ainda, "já os seres humanos possuem a capacidade de modificar, acomodar ou diferenciar os sons emitidos, dando-lhes significado. É isto a articulação, a fala. A voz é um elemento físico da linguagem e a sua base é anatomofisiológica". E finalmente "A linguagem é o fenômeno da comunicação entre os seres. É a transmissão dos conceitos através de elementos simbólicos e convencionados. A voz, a fala, a escrita, a audição e os gestos são exemplos de tais elementos".

Essas afirmações, apesar de confusas, como de resto também o são outros escritos sobre o mesmo tema ${ }^{3}$, parecem questionar a autonomia dos termos 'voz' e 'fala' mas, com certeza, não deslocam a linguagem de sua posição no campo fonoaudiológico. Deixaremos mais uma vez aos colegas especialistas naquelas áreas a palavra final, lembrando que um campo de saber somente será ciência quando da circunscrição de seu objeto - uno e único.

Passo, então, a expôr minhas reflexões sobre a fonoaudiologia definida enquanto disciplina clínica que toma por objeto a linguagem. Diria primeiro que o objeto de uma disciplina não é o objeto empírico mas aquele produzido teoricamente. Isto implica a necessidade de se explicitar sob qual concepção teórica se define linguagem, o que será apenas sinalizado neste texto. Retomaria as palavras de Althusser ${ }^{4}$ para dizer que uma disciplina é uma ciência particular de um objeto próprio, possuindo uma teoria e uma técnica (método) que permitem o conhecimento e a transformação desse objeto em uma prática específica. Diria, ainda, que ao afirmar que a linguagem é objeto e meio da prática fonoaudiológica estou me referindo a uma certa noção de linguagem, aquela pressuposta por uma semântica discursiva que coloca em contradição língua e discurso e que incorpora sujeito e sentido à estrutura. Esclareço, é necessário ultrapassar a descrição operada pela linguística das formas sobre a fala e alçar uma ciência da linguagem que irá atuar sobre o funcionamento do discurso do falante.

Retomo a problematização do estatuto de uma ciência. Se a Fonoaudiologia nasce de práticas clínicas, é a eficácia de seu fazer que levará alguns a acreditar na ultrapassagem de seu estatuto de atividade paramédica e a investir em sua teorização. Como já dizia Lacan, antes de existir a clínica psicanalítica, houve uma outra na qual esta se inspirou; 
a mesma afirmação pode ser tomada como verdadeira pela Fonoaudiologia. Antes do discurso fonoaudiológico, há outros que dão voz a esta disciplina. Falada, ou melhor, cantada em vozes dissonantes como as da Medicina, da Lingüística, da Psicologia e da Psicanálise, a Fonoaudiologia vislumbra uma possível autonomia consequente a sua recusa em se ver reduzida a qualquer outro campo de saber e pede a palavra. Eis um momento histórico: o do dito corte epistemológico. Para encurtar uma história longa, história já contada em outro lugar ${ }^{5}$, com a ruptura a Fonoaudiologia pede a voz e passa, como diz Freud, a querer "usar a moeda vigente no país" ou seja, a dizer de sí, de seu lugar, com seu olhar, nos termos e conceitos que têm a sua disposição.

Aquelas disciplinas, antes fundantes e determinantes, adquirem um novo estatuto: passam a ser interpeladas pela Fonoaudiologia. Neste novo tempo, o primeiro da identidade, a Fonoaudiologia redefine seu objeto promovendo forte deslocamento em suas relações de vizinhança. Se a psicanálise nasce órfã - nas palavras de Althusser - a Fonoaudiologia deseja o reconhecimento de uma maternidade que lhe poderá ser extremamente vantajosa. Definindo seu objeto como a linguagem, estreita laços de filiação com a lingüística e, se esta linguagem é aquela que se observa na fala do outro, aponta uma certa ciência da linguagem como o lugar para problematizar o funcionamento dessa mesma linguagem. As ciências que tomam como objeto a constituição dos sentidos da linguagem mostram-se como lugares exemplares para se poder observar processos quase indiscerníveis na leitura do leigo.

No entanto, o interesse da Fonoaudiologia pela linguagem ou mais acertadamente pela patologia da linguagem somente será validado sob a égide da clínica. É nesse momento que uma disciplina do final do século XX beneficia-se de seu nascimento tardio: há um pai nesta filiação, oficializando a união da linguagem em sua instância patológica com uma certa clínica, com a qual compartilha concepções, suporta crenças, vislumbra caminhos. Se à Lingüística é conferida a maternidade, com certeza a paternidade deve ser atribuída à Psicanálise.

Mas como não basta a relação parental para dar o estatuto de disciplina à Fonoaudiologia, cabe aos fonoaudiólogos a tarefa da literalização, da construção de um discurso sobre esse novo saber. Quando se fala em ciência, deve-se lembrar que, além da circunscrição de um objeto, deve-se poder dizer, alçando um sistema rigoroso de conceitos abstratos, como pensar, questionar, refletir e construir o espaço teórico que o envolve.

Concordamos com Althusser quando este afirma que a estrutura de uma ciência de clínica deve incorporar uma prática, uma técnica e uma teoria que coloque em relação esta prática com a técnica. Se assim funda-se uma ciência, podemos afirmar que a Fonoaudiologia é um campo de conhecimento cujo objeto é a linguagem - em seu funcionamento e em sua materialidade - privilegiando sua instância patológica; na seqüência um campo de vocação clínica, principalmente terapêutica.

Se já é possível dizer-se da Fonoaudiologia, ou seja definí-la, localizá-la, é preciso agora passarse para um outro enfrentamento: pensar em como será o método clínico. Mas como pensar no método, sem, paralelamente, pensar na questão da nosologia? Ou melhor, como constituir um método sem re-significar a noção de doença e de seu diagnóstico? Um bom começo, com certeza, seria discernir a patologia de linguagem de outra que sempre foi dita num discurso médico ou seja no discurso da objetividade. Não é mais possível pensar-se na clínica sem a releitura decorrente da redefinição do objeto. Me explico melhor: se o objeto é a linguagem em seu funcionamento, fala-se aqui de uma subjetividade. Assim a clínica médica perde a voz, pois seu objeto é de uma outra natureza. Cabe à Fonoaudiologia, portanto, pensar a nosologia em outro lugar.

Uma nosologia pode ser proposta em dois planos: o das estruturas e o dos tipos. Por que outra razão a nosologia é necessária? Primeiro porque o objetivo da clínica, anterior ou concomitante à cura, é a detecção da estrutura e do tipo clínico da patologia de linguagem do falante. Assim nas primeiras entrevistas ou entrevistas preliminares (Termo cunhado por Lacan, sobre o que Freud chamou de tratamento de ensaio), é importante - uma vez definida a estrutura - ultrapassar o plano desta para chegar ao dos tipos clínicos, o que permitiria ao terapeuta vislumbrar a direção da terapia, sem a qual o processo terapeutico ficaria à deriva. Há, portanto, uma relação de implicação entre diagnóstico e terapia, como quer Quinet ${ }^{6}$, depois de Freud e Lacan: se diagnóstico então clínica terapêutica. Ou seja, o sentido do diagnóstico está em servir de guia para a condução da terapia. Assim, repito mais uma vez, se o diagnóstico médico é construído no plano da objetividade, o diagnóstico fonoaudiológico - porque assentado sobre o funcionamento da linguagem - o será no plano da subjetividade.

Por onde então começar? Inspirados em estudos sobre a linguagem que a tomam em seu funcionamento e assumindo um duplo compromisso, como diz Carielo da Fonseca ${ }^{7}$ - "compromisso antes de tudo com a linguagem do paciente $e$ acima de tudo, com a ordem da linguagem". Nestes dois compromissos materializamos a relação com a Lingüística e com a Psicanálise. Do ponto de vista 
da lingüística, vamos identificar a linguagem deslizando em dois eixos, o metafórico e o metonímico. Se a fala do adulto mostra o Real da Língua apenas nos equívocos, nas falhas, no erro, no lapso, o lugar exemplar para que a lingua se mostre para a Fonoaudiologia são os estudos sobre a aquisição e a perda da linguagem. A aquisição porque nela pode-se, claramente, identificar o funcionamento de cada um desses eixos. A heterogeneidade da linguagem da criança, tão discutida nos trabalhos de De Lemos, se dá a ver não apenas sob a forma de discrepâncias e de erros corrigíveis, mas também sob a forma de enunciados insólitos, não-corrigíveis que apontam para a imprevisibilidade da lingua e do seu efeito sobre o falante ${ }^{8}$. E na perda porque no discurso afásico o esgarçamento do simbólico permite que se entreveja a relação de contradição que se opera entre língua e discurso.

Resumindo, diríamos que interessa ao fonoaudiólogo uma concepção de linguagem que Ihe permita ver a linguagem em seu funcionamento, ou ainda a linguagem em sua singularidade. A patologia de linguagem, portanto, indiciaria um funcionamento peculiar do simbólico. O objetivo da clínica fonoaudiológica será então conhecer esse funcionamento e nele intervir usando a própria linguagem como forma de sustentar e estruturar a linguagem do paciente.

Se o primeiro passo já foi dado, o caminho a ser percorrido por uma disciplina em constituição requer persistência. É preciso inaugurar o discurso fonoaudiológico revisitando nosso passado de forma crítica e reconhecendo o espaço terapêutico como o lugar privilegiado da problematização e teorização da Fonoaudiologia. É preciso legitimar o fonoaudiólogo como terapeuta, diferenciando-o do educador, do professor ou do reabilitador através da construção de um método inspirado na clínica do dizer. Desta forma, o fonoaudiólogo, ao interpretar o dito, ora do ponto de vista de um dizer que denuncia a posição do outro - a fala dos pais nas entrevistas preliminares -, ora do ponto de vista de seu funcionamento - a fala do paciente no processo terapêutico -, afastará a ameaça de nova dominação ao marcar a distinção entre as formas de interpretação que identificam a clínica fonoaudiológica e a particularizam em relação à clínica psicanalítica.

Portanto, se cada forma de conhecimento tem seu objeto, com certeza a Fonoaudiologia estará alçando o estatuto de ciência particular ao afirmar os distúrbios de linguagem e sua terapêutica como seu espaço de atuação clínica.

\begin{abstract}
This paper discusses Speech and Language clinic as a science, particularly the definition of its object of study and its subdivision aiming at the consolidation of its status as science. It is assumed for the purpose of this argumentation, that the object of study for Speech-Language pathology is the clinical approach to language and its pathological process, as long as language is considered as the symbolic instance of subjectivity constitution. If it is assumed that this hypotheses is true, there are two major consequences: Audiology would be understood as a branch of biological sciences and therefore would not share the same object of Speech-Language pathology, and second, would stand against the understanding of Speech-Language clinic as a mere practice. On the other hand, this conception defines the speech-language therapist as a clinician, involved with the patient's language and its cure. Furthermore, it recognizes Linguistics and Psychoanalysis as sciences of peculiar interest for the speech-language therapist since that they share with Speech-Language pathology the same concept of language and subject. Once that Speech-Language pathology is redefined, it will face the task of recognizing the clinical practice as the locus of and therefore will have to discuss the constitution of its clinical method. Finally, this paper brings to the attention of the speech-language therapist the threat of a new domination in case of particular forms of interpretation of Speech-Language pathology clinic not being distinguished from the psychoanalytic practice.
\end{abstract}

KEYWORDS: Speech, Language and Hearing Sciences; Science; Speech-Language Pathology; Language 


\section{REFERÊNCIAS}

1. Freire RM - O objeto da Fonoaudiologia. Texto inédito apresentado no II Seminário Introdutório promovido pela Faculdade de Fonoaudiologia da PUC-SP. 1996.

2. Amorim A. Fonoaudiologia Geral, São Paulo: Ed.Livraria Pioneira Editora, 1972.

3. Cappelletti I. A Fonoaudiologia no Brasil, São Paulo: Cortez Editora,1985.

4. Evangelista WJ Louis Althusser - Freud e Lacan, Marx e Freud, $2^{\mathrm{a}}$ ed., Rio de Janeiro: Graal, 1985.
5. Cunha MC. Deslizamentos e Deslizes do Campo Fonoaudiológico em Fonoaudiologia e Psicanálise: a fronteira como território, São Paulo: Ed.Plexus, 1997.

6. Quinet $A-A s 4+1$ condições da análise. Rio de Janeiro: Jorge Zahar Editor.

7. Fonseca, SC A instância clínico-terapêutica na Fonoaudiologia. In Freire,R. (org.), Interfaces ํo3, série Linguagem.São Paulo, Ed. Roca, 2000 pag.69-78.

8. De Lemos CTG. Língua e discurso na teorização sobre aquisição de linguagem. Letras de Hoje, Porto Alegre. 1995;30(4):9-28.

Endereço para correspondência:

Regina Maria Ayres de Camargo Freire

Rua Heitor de Andrade, 170

São Paulo, SP

CEP: 05441-020

E-mail: freireregina@uol.com.br 